removed. Gave one-sixth of a grain of tartar-emetic to keep up the sedative effects of the bleeding; applied cold to the face. -Nine A.M.: Mr. Stevenson, Mr. Hamilton, Dr. Walker; Dr. Robertson, and Mr. Macdougall met. Patient very composed; pulse soft, and 108; countenance extremely pale; eyelids drooping. Tocontinue the mix ture in half-ounce doses, and only every four hours. Dr. Walker remained till next consultation.-One P.M.: Same medical gentlemen present. Features of patient not so pale; pulse 112, but soft, and less jerky, and somewhat irregular. Continue the mixture without the foxglove. Apply a large blister to left side of chest. Dr. Vose sent for-Halfpast four P.M.: Dr. Vose, of Liverpool, Mr. Stevenson Mr. Hamilton, Dr. Walker, Dr. Robertson, and Mr. Macdougall present. It was agreed that the patient was most probably the subject of tubercles in the lung, which acted as a predisposing cause of the hæmorrhage, the inhalation of chloroform serving as the exciting cause. The air appeared now to enter the tubes of both lungs pretty freely; but the left side appeared to expand less than the right during inspiration, whilst the respiration was rather bronchial in character on that side; no crepitation was now audible on either side; a few dark clots were occasionally expectorated. To continue the acetate of lead mixture, and to-morrow morning to commence with a purging mixture of sulphate of magnesia and infusion of roses. -Nine P.M.: Mr. Stevenson, Dr. Walker, and Mr. Macdougall present. No return of the hæmorrhage; a little inclination to cough. To reduce this, the one-twelfth of a grain of tartar. emetic, with two grains of extract of henbane, was ordered in solution every three hours, besides the lead mixture. Mr. Macdougall remained all night.

14th.-Nine A. M.: Mr. Stevenson, Dr. Walker, Dr. Robertson, and Mr. Macdougall met. Patient appears to be doing well. Pulse quiet; bowels not open. The sulphate of magnesia mixture every two hours until the bowels are affected. Four P.M.: Dr. Vose, Mr. Stevenson, Dr. Walker, Dr, Robertson, present. Bowels not opened by mixture. An enema ordered.-Nine P.M.: Dr. Walker and Mr. Macdougall met. Patient continues better. Bowels opened by enema; both lungs acting freely; occasionally a small dark clot expectorated; patient complains of severe heartburn, from the sulphate of magnesia mixture, to check which he has taken some of Murray's fluid magnesia. Continue the hyoscyamus and tartar-emetic, and the lead mixture if necessary. Dr. Walker and $\mathrm{Mr}$. Macdongall remained till after twelve P.M., when they left the patient quiet and asleep, with a soft pulse of 106 .

15th.-Dr. Walker and Mr. Macdougall sent for in haste at half-past seven A.M. Hæmorrhage returned to nearly three ounces, in one gush, and followed by fatal syncope. Heart ceased to beat at twenty minutes past eight A.M.

Copy of the Depositions \&c. touching the Death of John William Johnson Anderson, before Henry Churton, Esq., Coroner, March $17 t h, 1848$.

James Hunter Robertson deposed-I am a physician, practising at Birkenhead; I knew the deceased, John William Johnson Anderson, who was a physician, aged twenty-three years. The deceased formerly practised at Birkenhead, but had latterly relinquished his profession. The general health of the deceased was good, although he had the appearance of being a delicate person. On Saturday night last, at about eleven o'clock, I was requested to visit the deceased, who, I was informed, had ruptured a bloodvessel. I found him much agitated, and vomiting blood, which was florid and apparently arterial. Mr. Macdongall, (the resident hospital surgeon, of Birkenhead,) who had also been sent for, shortly arrived, and, after a consultation, the deceased was bled. I remained with the deceased about an hour, and left him, much better, in the care of Mr. Macdougall. I visited the deceased each day until Wednesday last, when he expired. The deceased informed me he had inhaled chloroform on Friday last, before the extraction of a tooth, and that it had been administered by $\mathrm{Mr}$. Wain wright, the dentist, of Birkenhead. The deceased did not complain of having experienced any ill effects from it. I cannot state what gave rise to the hremorrhage. I have used chloroform indiscriminately, without the slightest ill effect, and have kept my patients under its influence from four to five hours; about half a drachm is the quantity I have used to produce the desired effect. To keep a person under its influence four or five hours, I have used about an ounce of it. I cannot state what effect chloroform has upon the lungs; it produces insensibility by deadening the nervous system. I frequently use chloroform in midwifery; my opinion is, that the deceased died from natural causes, and not from the effects of chloroform.

(Signed) J. Hunter Robertson, M.D.
William James Macdodgall deposed: "I am the medical officer of the Birkenhead Hospital. On Saturday night last, at about twelve o'clock, I visited the deceased, Mr. Anderson, whom I found at his residence in Church-street: on my way down, I took Dr. Walker with me. I found that the deceased had expectorated about six ounces of arterial blood, which I judged had been expectorated from the lungs, having examined the chest, and found the deceased labouring under symptoms of pulmonary apoplexy. The deceased was bled, and $I$ remained with him during the whole of the night. In conversation, Mr. Anderson informed me he had felt himself growing gradually weaker for some time. He asked me if I thought the hremorrhage from the lungs was occasioned by the inhalation of chloroform. I said I thought it might. The deceased said he could not attribute it to any other cause; and moreover, said he had felt much depressed during the day.

"The deceased was most probably suffering from tubercles of the lungs, and I think the exciting cause of the hrmorrhage was the inhalation of chloroform; brandy-and-water, or any other stimulant, might also give rise to hæmorrhage from the lungs. Chloroform would produce pulmonary congestion, and ought to be most carefully administered. I would not use chloroform indiscriminately. I would not have given chloroform to the deceased, suspecting, as I did, that he laboured under an affection of the chest."

(Signed) Wruhiam Jamas Macdovgahr.

Mary Pratr deposed: "The deceased had resided at my house, in Church.street, Birkenhead, about twelve months. I considered his health delicate; he suffered much from de. bility. His habits were particularly abstemious. He complained of great languor for three weeks prior to his death. He attributed it to influenza. He also suffered from pain in his back. On Friday afternoon last, the deceased had a tooth extracted; and on his return home he seemed quite cheerful and excited. On the following morning he appeared much better, although somewhat excited, but still not so much so as he had been on the previous day. The deceased went to Liverpool, and returned at about seven o'clock in the evening; complaining of pain in his back, and also of depression and debility. He partook of some cocoa, and retired to bed at his usual hour, when he was suddenly seized with vomiting of blood. The deceased informed me he had had an unusually long walk in Liverpool, and had felt unable to bear it."

$$
\text { (Signed) Marx PratT. }
$$

Verdict.-Djed from "hæmorrhage from the lungs;" but how the hæmorrhage was produced there is no evidence to prove.

** This case, and that which we published in Tne Larcer of July 1st, are eminently calculated to warn practitioners that the employment of chloroform is peremptorily contraindicated in cases in which the organs of the thoracic cavity are found to be seats of disease. The impression that such would eventually prove to be the fact was announced in THE LANCET of January 1st in the present year, before any known fatal occurrence from its use in the human subject had taken place. This opinion, announced by Mr. Thomas Wakley, was a natural corollary resulting from the appearances presented on the post-mortem examination of numerous animals on which he had experimented. The account of his experiments will be found in our number for January 1st, already quoted, and to which the reader is referred; but in this place we may appropriately reproduce the reflections to which the experiments gave rise:-

"The results of some of the above experiments warrant, $I$ think, an important practical application. On some points at least no room remains for doubt. An examination of two or three facts irresistibly impels the mind to this conclusion. Only four days previously to the death of that cele brated surgeon, whose loss is truly a national calamity, the sufferer himself, while labouring under a paroxysm of dyspnoea, thought that he might possibly find relief from the inhalation of the vapour of chloroform. The suggestion was adopted; the vapour was administered, but necessarily without any beneficial result. Why necessarily? Because the post-mortem examination exhibited lungs that were ' engorged throughout, and an 'aneurismal sac' near to the heart. Under such circumstances of disease, and in such a condition of the lungs, a more unfortunate or dangerous remedial agent than the chloroform could not have been 
employed. This is now incontestably proved by the dissections in the instances in which death followed the experiments which I have just recorded. The examinations prove that blood, almost black, had collected in the heart and lungs, and the great vessels connected with those organs to a degree of intensity which was probably never surpassed. Anything of the kind more striking probably was never wit nessed in post-mortem examinations. What, then, is the practical application of the facts which are thus brought under our consideration? Why, obviously and necessarily, that when there exists any disease of the heart, any aneurisin near to the heart, any threatening dyspnœa, or any tendency to an 'engorgement of the lungs,' it would be highly imprudent to recommend the inhalation of the vapour of chloroform or of ether; but that in any of the abnormal conditions here described, should the practitioner determine upon employing one of the two agents in question, assuredly the more dangerous one of the two would be found in the vapour of chloroform."

In the Dublin Medical Press for last week we find the following extract. Such a reaction of opinion as it indicates is a very natural result of so many authentic instances of death supervening on the employment of chloroform having gained publicity.

"Chloroform in the United States.-The anæsthetic excitement which prevailed a short time since has rapidly subsided, as we anticipated it would. The occurrence of fatal consequences in several instances in which ether and chloroform were administered, particularly the latter, has cast a dark shade over the use of these agents. The danger now is that we shall run into the opposite extreme, and instead of having recourse to these remedies for pain in trifling cases decline to employ them in those in which they may be most necessary and proper."-Quoted from the Philadelphia Medical Examiner, May, 1848.

\section{NOTE ON THE}

RELATIONS OF THE GALVANIC INFLUENCE TO THE NERVOUS AND MUSCULAR SYSTEMS, AND AS A THERAPEUTIC AGENT.

By MARSHALL HALL, M.D., F.R.S., \&c.

No one can have formed a higher opinion of the admirable labours of Signor Matteucci than myself. If I had an adverse opinion to state, it would be, that the Italian professor does not, in the course of what he designates his "electro-physiological" researches, always distinguish between physiological and pathological effects. Thus, he observes that the inverse current, made to pass through a nerve, induces tetanoid phenomena on breaking; but that the direct current does not; and this statement is, of course, repeated by Dr. Todd. It is an error. Again, Signor Matteucci says that the "alternative Voltaique" cannot be produced in a muscle deprived as much as possible of nerve. This is an error, too. These errors I believe to have arisen from not attending to the varied phenomena produced by varied degrees of force in the voltaic influence employed, and between the consequent physiological and pathological effects produced.

In every point of view it would be most important to ascertain distinctly the effects of different forces-of different powers in the apparatus, therefore of the continued and interrupted current-and therefore of the different forms of apparatus, which are not only different, but even opposite in their effects - the former being actually sedative, the latter, excitant or stimulant; and lastly, of the various kinds of conductors which may be employed.

All this is essential if we wonld ascertain the therapeutio value of electricity - an agent of great power for evil as well as good, as at present used by the ignorant empirics.

I was carefully pursuing this subject with the aid of my able friend, Mr. Henry Smith, and sent the commencement of a destined series of papers to the Royal Society. It is well known that Signor Matteucci was pursuing a similar not an identical course. Having ascertained the physiological effect of the galvanic influence on muscular nerves, my further object was to ascertain those effects on the centre of the SPINAL SYSTEM, then on its incident nerves, and then on the nervi-muscular fibre-objects which conld scarcely be entertained by the natural philosopher of Pisa, and which, in fact, were not-that eminent person's investigations being expressly brought to a close without any allusion to these questions. I mention these facts merely to show that our investigations, in their objects and aims, were not the same.

Now it happens that I sent the first part of my paper to the Royal Society in March, 1847; Signor Matteucci sent a part of his series in June of the same year, three months afterwards. The chief facts-fact for fact-in these two papers, are identical. They are the facts relating to muscular nerves. Mine led to the investigation into the relation of galvanism to the spinal marrow and incident nerves, a paper on which was sent soon afterwards, in May; Signor Matteucci's led to nothing ulterior. Sionor Matteucci's paper was printedmine blackballed! I am sure that Signor Matteucci himself will not be flattered by such an act of favouritism towards himself, coupled with such injustice to another.

Besides, the investigation ought to be prosecuted. By whom shall it be done? and through what channel given to the public? I have bestowed the evenings of nearly two winters on this labour.

The question was not one of the nature of facts, for they were the same; nor of priority, for my paper had the priority; nor of utility, for mine alone went on to the useful and the practical; nor-but it is in vain to proceed; the thing is altogether incomprehensible on any principle of logic, of common sense, or of justice.

It is admirable to observe how the persistent effects produced by a continued galvanic current-the electrogenic state -in the different series of nerves, represent the TrPES of disease in the spinal system, especially when contrasted with the effects of strychnine. It is obvious that these conditions could not be made intelligible to any but a medical person, and therefore could not be investigated by the philosopher of Pisa. Again, I ask, by whom, and how, shall this work be done and published?

I-shall not add a remark on a proceeding which needs only to be pointed out.

Manchester-square, June, 1848

\section{Analnoss}

\section{COMMUNICATIONS IN MS. RECEIVED FOR PUBLICATION IN THE LANCET.}

"L'auteur se tue à allonger ce que le lecteur se tue à abréger."

Epileptic Fits removed by Sulphate of Zinc.

Mr. WATsoN, of Wanlock-head, Dumfriesshire, narrates the following case:-

“J. H H aged thirty.one, and unmarried, has been subject to epilepsy since she attained the age of fourteen years She first menstruated about that time, and the epileptic fits returned regularly every six weeks afterwards, except once, when, owing perhaps to her having received a severe burn on the chest and neck from falling on the fire during one of the attacks, the succeeding interval was three months. She is tall, and generally healthy; menstruates every four weeks; her appetite is good; her bowels regular; she has no aura, nor is she apprized of the approach of the fits in any way whatever. She is generally engaged in household matters, and occasionally employed out of doors. Previous to 1846 , several medicines had been tried for the purpose of removing or alleviating the complaint, and about the commencement of that year sulphate of zinc was administered. At first, the dose was two grains daily in solution, and for a few weeks it appeared to have little effect, but in process of time the intervals became longer and on the 16th December, 1846, when she had a return of the paroxysm, the interval had extended to sixteen weeks. I then increased the dose to three grains daily, and she remained perfectly well until the middle of May, 1847, when she had another attack. In the end of June she had a second, and about the middle of September a third, in consequence of which I angmented the quantity to four grains daily; since that time she has had no return of the complaint. In this instance, at least, the urse of zinc has been attended with the most beneficial effects, it having not merely lessened the excitability of the system, and broken the habit of periodicity, but actually rendered the patient entirely free from the malady for nearly forty weeks. Nor can the improvement experienced be attributed to any other cause, such as free exposure to the open air, exercise, ablution, regimen, \&c., as no greater attention was paid to these things during the use of the medicine than had been done previously. 